\title{
Radiative Characteristics of Cirrus Clouds as Retrieved from AVHRR
}

\author{
Shuichiro KATAGIRI and Teruyuki NAKAJIMA \\ Center for Climate System Research, The University of Tokyo, Tokyo, Japan
}

(Manuscript received 1 August 2003, in final form 8 October 2003)

\begin{abstract}
An algorithm is developed to retrieve the effective particle radius, cloud optical thickness, and cloud top temperature of cirrus clouds on a global scale using two infrared window channels and a nearinfrared channel of the National Oceanic and Atmospheric Administration (NOAA) Advanced Very High Resolution Radiometer (AVHRR) on board NOAA-9 and NOAA-11. In the algorithm, overlapped cloud cases are taken into account. Data from the satellites are reconstructed to segmented data that contain a hundred satellite pixels in each $0.5^{\circ} \times 0.5^{\circ}$ latitude and longitude grid. The algorithm is applied to fourmonth segmented AVHRR Global Area Coverage data from 1986 through 1994. The resulted cloud parameters are compared with airborne measurements and the products of International Satellite Cloud Climatology Project (ISCCP). These comparisons show that the effective radius obtained by this algorithm is smaller than that by airborne measurements, and that the cirrus cloud top temperature is about $5 \sim 20 \mathrm{~K}$ lower than that of ISCCP. The global distribution, and the time series of these parameters, are shown and discussed.
\end{abstract}

\section{Introduction}

Cirrus clouds are recognized to cover permanently more than $20 \%$ of the earth (Liou 1986; Hartmann et al. 1992; Liao et al. 1995a; 1995b), and to play an important role in the earth's radiative budget (Charlock and Ramanathan 1985; Baker 1997; Ramanathan 1987; Hansen et al. 1998; Ramanathan et al. 1989). The radiative forcing of cirrus clouds at the top of the atmosphere (TOA) can be either positive or negative through two opposite effects: they partly reflect the solar radiation and therefore cool the atmosphere, while they partly interrupt the infrared radiation from the earth and thereby warm the atmosphere. These competing effects depend complicatedly on their

Corresponding author and current affiliation: Shuichiro Katagiri, Earth Observation Research and Application Center, Japan Aerospace Exloration, Harumi Island Triton Square, Office Tower X 22F, 1-8-10, Harumi, Chuo-ku, Tokyo 104-6023, Japan.

E-mail: katagiri@eorc.jaxa.jp

(C) 2004, Meteorological Society of Japan abilities of absorption, scattering and emission, which are determined by their microphysical properties (i.e., cloud optical thickness, ice particle size, shape, etc.) and physical conditions (i.e., cloud temperature, geometrical structure, etc.) (Wielicki et al. 1995). Although General Circulation Models (GCMs) are used to study the role of clouds, the modeled cloud processes are insufficient yet in treating the radiative properties and their feedback processes (Randall et al. 1989). Different parameterizations of the cloud processes produce large differences among the climate sensitivity values of clouds calculated by various GCMs (Cess et al. 1990; IPCC 1996; 2001).

In recent years, global satellite data of the microphysical properties become available, especially for low clouds (Han et al. 1994; Han et al. 2002; Kawamoto et al. 2001). But there is still scarce information about the cirrus clouds distribution and their properties to evaluate their impact on the global radiative budget (Liou 1986; Stephens et al. 1990). Recent observations have been carried out by several 
techniques, such as lidar and high frequency radar observation from ground, ship and aircraft (e.g., Spinhirne et al. 1996; Mace et al. 2001; Okamoto et al. 2003). But their coverage and frequency are not enough to satisfy the requirement for the global scale study. Remote sensing from space is, on the other hand, capable of giving us ample information over the globe and nearly daily observation, so that an improvement of satellite remote sensing techniques is expected to make a large impact on the cirrus studies.

To detect cirrus clouds from space is very difficult owing to their semi-transparency. Cirrus clouds are often difficult to be recognized at visible wavelengths, and to be separated from the ground or sea surface or low level clouds at infrared wavelengths. Inoue $(1985 ; 1987 ; 1989)$ studied the effective emissivity of cirrus clouds, and proposed a cloud type classification by using two wavelengths, 11 and $12 \mu \mathrm{m}$. Ou et al. (1993; 1995) developed a retrieval scheme using 3.7 and $10.9 \mu \mathrm{m}$ wavelengths, and they have calculated cirrus cloud optical thickness and mean effective crystal size simultaneously from the two wavelength radiances. Ou et al. (1996) developed a technique of cloud classification to identify cirrus, cirrus with low clouds, and low clouds. A three-channel technique with 3.7, 11 and $12 \mu \mathrm{m}$ radiances was proposed by Lin and Coakley (1993) in order to take account of ambiguous cloud coverage within mesoscale regions.

These algorithms have been applied mostly to local area data. Giraud et al. (1997) analyzed the cirrus cloud distribution over Europe, and the North Atlantic Ocean, with the collective analysis method using two wavelengths diagram. But the analysis area was still not large enough for global scale discussion. The only product of global distribution of cirrus cloud parameters is the result from the International Satellite Cloud Climatology Project (ISCCP) (Schiffer and Rossow 1985; Rossow and Schiffer 1991; Rossow et al. 1996). This product covers a long period and contains the parameters of various cloud types including those of cirrus (Stowe et al. 1989; Wylie et al. 1994; Wylie and Menzel 1999). However, this product was retrieved with a simple one channel threshold method and does not include the effective radius of cirrus clouds.
Under the circumstance mentioned above, more global scale studies are needed for retrieving the cirrus cloud parameters from satellite observations. Accordingly, we propose in this paper a simultaneous analysis of the optical thickness, effective radius, and cloud top temperature of cirrus clouds over a global scale. In our three-channel infrared method, three wavelengths, channel $3(3.7 \mu \mathrm{m})$, channel 4 $(10.8 \mu \mathrm{m})$, and channel $5(12.0 \mu \mathrm{m})$ of Advanced High Resolution Radiometer (AVHRR) on board NOAA-9 and NOAA-11 are used, and the scheme is applied to four months data acquired from 1986 through 1994 over the latitudinal region between $60^{\circ}$ north and $60^{\circ}$ south.

\section{Retrieval method of cloud properties}

\subsection{Split window method}

It is known that the split window method, proposed by Inoue (1987), is useful for detection of cirrus clouds, which uses two infrared window wavelengths, such as 10.8 and $12.0 \mu \mathrm{m}$. Figure 1 illustrates an example of the signals from a satellite used in the split window method, which is calculated with the radiative transfer model (Nakajima and Tanaka 1986;

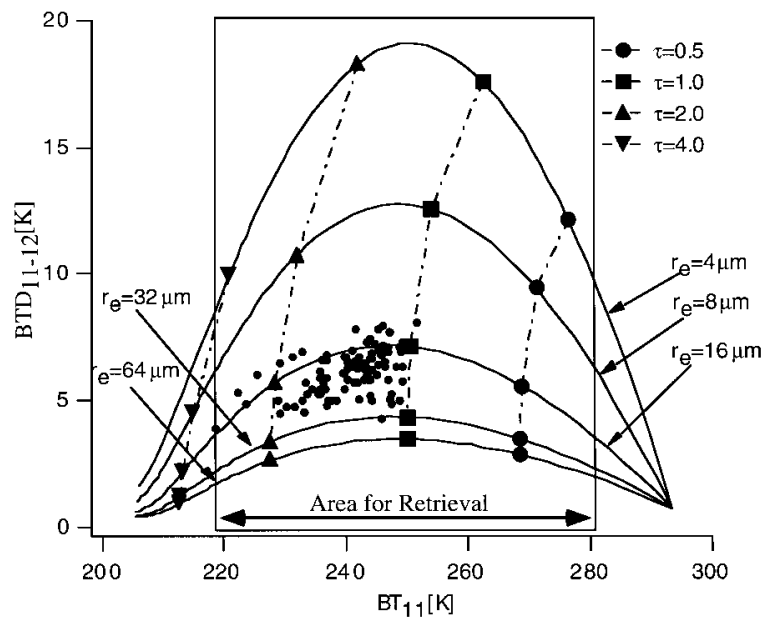

Fig. 1. Brightness temperature difference between 10.8 and $12.0 \mu \mathrm{m}$, BTD $_{11-12}$, as a function of brightness temperature at $10.8 \mu \mathrm{m}, \mathrm{BT}_{11}$. The box indicates the area for retrieval to ward off error caused by congested look up table data. Hundred pixel data from AVHRR are also shown for the 11th of January, 1990. 
1988) (see 2.2). Theoretical brightness temperature difference (hereafter referred to as BTD $_{11-12}$ ) curves between 10.8 and $12.0 \mu \mathrm{m}$ are plotted as a function of the corresponding brightness temperature (hereafter $\mathrm{BT}_{11}$ ) at $10.8 \mu \mathrm{m}$ for the cirrus cloud. It is recognized in Fig. 1 that the brightness temperature emitted from the vicinity layer to surface can be retrieved from pixels without clouds or with optically very thin clouds, while the cloud top temperature can be gotten from pixels with optically very thick clouds. The figure also shows that the BTD becomes large for clouds with moderate optical thickness. We plotted a hundred AVHRR pixel data in a $0.5^{\circ} \times 0.5^{\circ}$ longitude-latitude segment grid consists of cirrus clouds for 11 January 1990. The brightness temperature of cirrus clouds obtained from space appear to be having the brightness temperature between the cloud top temperature and the ground temperature under the clouds due to their optical semi-transparency, and in the typical cirrus clouds cases, data are distributed like an example of the signals in Fig. 1. Therefore, we can apply this split window method to retrieve the cirrus cloud optical thickness, $\tau$, and the cirrus cloud effective particle radius, $r_{e}$. In the case of Fig. 1 the cloud parameters are retrieved in the range of $\tau_{c}=$ $0.98 \sim 3.2$ and $r_{e}=13.8 \sim 33.2$.

To explain the dependence of BTD to the cloud parameters, we consider a simplified cloud-ground model, in which $B_{g}$ and $B_{c}$ indicate Planck functions for the ground surface and the cirrus cloud, respectively, $t$ and $\varepsilon$ are the transmissivity and emissivity of the cirrus cloud layer, respectively, and $n$ is the cloud fraction of the field of view. The radiance $L$ received by the satellite can be given as

$$
L=n\left(\varepsilon B_{c}+t B_{g}\right)+(1-n) B_{g} .
$$

The temperature range in most cases is narrow, between about 200 and $300 \mathrm{~K}$, so that the Planck function can be roughly approximated by a linear function as

$$
\begin{aligned}
& B(T) \approx \alpha\left(T_{g}-T\right)+B_{g} \quad \text { and } \\
& L \approx \alpha\left(T_{g}-T_{B}\right)+B_{g},
\end{aligned}
$$

where $\alpha$ is the approximated linear coefficient and $T_{B}$ is the brightness temperature for the radiance L. From Eq. (2) and the relation $t+r+\varepsilon=1$, Eq. (1) can be rewritten as

$$
T_{B} \approx T_{g}-n\left(\varepsilon\left(T_{g}-T_{c}\right)-r B_{g} / \alpha\right),
$$

and thus the BTD between two wavelengths is expressed as

$$
\Delta T_{B} \approx n\left(\Delta \varepsilon\left(T_{g}-T_{c}\right)+\Delta r B_{g} / \alpha\right),
$$

where $\Delta T_{B}$ is the BTD difference, $\Delta \varepsilon$ and $\Delta r$ are the differences of emissivities and reflectivities at two wavelengths 10.8 and $12.0 \mu \mathrm{m}$, defined respectively as

$$
\begin{aligned}
& \Delta T_{B}=T_{10.8}-T_{12}, \quad \Delta \varepsilon=\varepsilon_{12}-\varepsilon_{10.8}, \\
& \text { and } \Delta r=r_{12}-r_{10.8}
\end{aligned}
$$

Consequently the cause of the brightness temperature differences (BTD) is thought to depend mainly on the difference of emissivities and reflectivities between two wavelengths. The amplitudes of $\Delta \varepsilon$ and $\Delta r$ are further related to the cloud particle size and cloud optical thickness as illustrated in Fig. 2(a) as a function of cloud optical thickness with a twostream approximation for two types of cirrus clouds that have effective radii of 10 and $30 \mu \mathrm{m}$. The figure shows the dependence of the BTD mainly depends on the emissivity difference $\Delta \varepsilon$. Here we define the effective radius $r_{e}$ by

$$
r_{e} \equiv \frac{\int_{0}^{\infty} r^{3} n(r) d r}{\int_{0}^{\infty} r^{2} n(r) d r},
$$

where $n(r)$ is the number size distribution as a function of particle radius $r$. As a conclusion, we can apply this split window method proposed by Inoue (1987) to the retrieval of the effective radius and optical thickness of cirrus clouds. Figure 2(b) also shows the theoretical BTD change as the column water vapor amount changes from a reference value of the tropical atmosphere model. The figure shows the water vapor effect is small for retrieving the cloud parameters as compared to the large effect of cloud parameters to the emissivity and the reflectivity of the cloud layer, although the water vapor effect is getting larger as the cloud optical thickness is getting thinner. Furthermore, we introduce the equivalent water vapor amount $w_{e}$ defined as

$$
w_{e}=\int w(z)\left(P(z) / P_{g}\right)^{0.9}\left(T_{g} / T(z)\right)^{0.5} d z
$$

to reduce the effect of atmospheric vertical pro- 

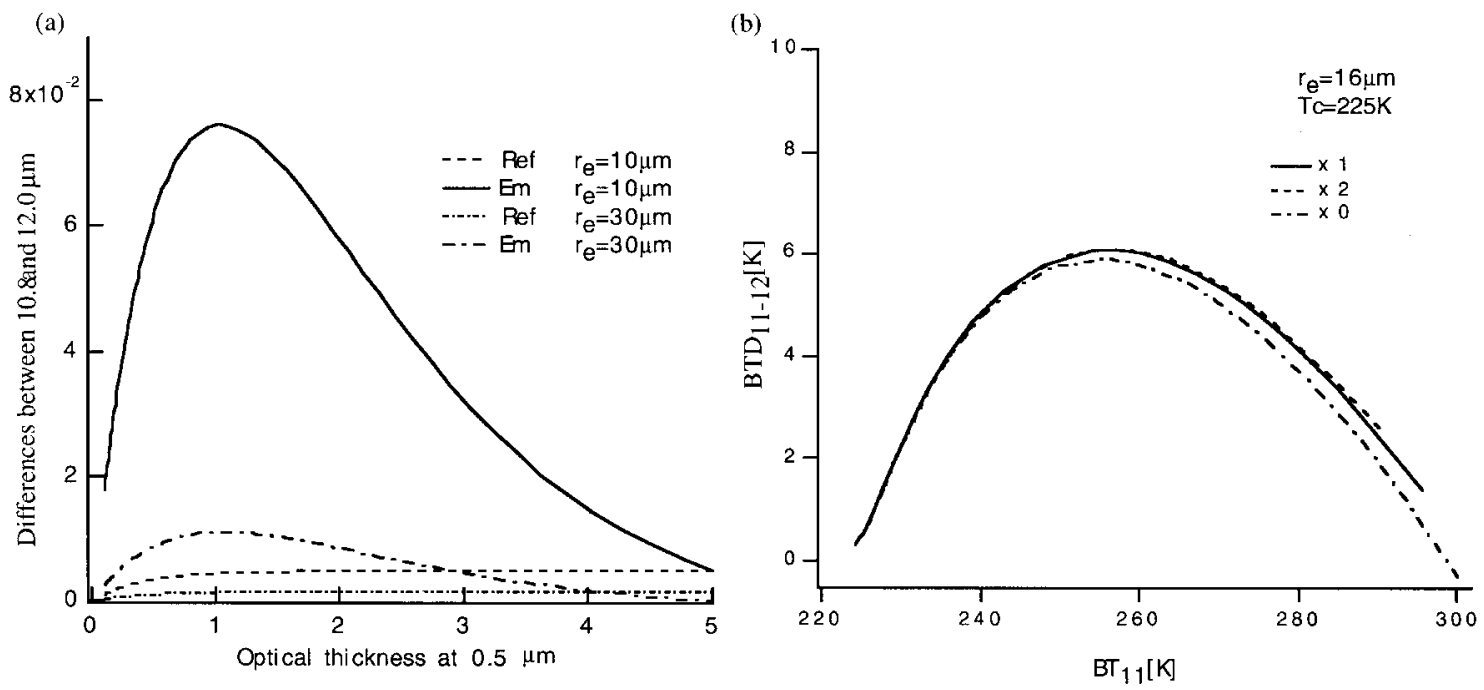

Fig. 2. The left panel shows reflectivity and emissivity differences between 10.8 and $12.0 \mu \mathrm{m}$ as a function of cloud optical thickness for two types of cirrus clouds that have effective radii of 10 and $30 \mu \mathrm{m}$. The right panel shows theoretical BTD curves with various water vapor amounts and with $r_{e}=16 \mu \mathrm{m}$ and $T_{c}=225 \mathrm{~K}$. The water vapor profile is from the profile of the tropical atmosphere multiplied by a factor of 0,1 , and 2 .

files (mainly water vapor, pressure, and temperature profiles) at each location on the earth (Kawamoto et al. 2001). In Eq. (7) $P_{g}$ and $T_{g}$ are the surface pressure and the surface temperature, respectively; $w(z), P(z)$ and $T(z)$ are the water vapor $\left(\mathrm{g} \mathrm{cm}^{-3}\right)$, air pressure, and temperature $(\mathrm{K})$ vertical profiles as a function of altitude $z$, respectively. We also calculated the effects by other gas concentrations, but these are found to be negligible. The effect of satellite zenith angle was found to be insignificant for retrieving the effective particle radius from BTD curves, whereas it is important for the optical thickness retrieval.

\subsection{Radiative transfer model}

In this study, we first investigate the variation of BTD curves received by the satellite for various parameters of atmospheric models. For calculating BT and BTD observed from the satellite, we use an accurate and efficient radiative transfer scheme with a combined discreteordinate-matrix-operator method, RSTAR-5b, one of the packages in the System for Transfer of Atmospheric Radiation (Star) (Nakajima and Tanaka 1986; 1988) extended to include thermal radiative transfer as proposed by Stamnes et al. (1988). In the radiative transfer calculation, we use the gas absorption model of
LOWTRAN-7 (McClatchey et al. 1972; Kneizys et al. 1988; 1990), and five Air Force Geophysics Laboratory (AFGL) model atmospheres, tropical, mid-latitude summer, mid-latitude winter, sub-arctic summer, and sub-arctic winter. A cirrus cloud model is adopted with volume equivalent spherical ice particles with the refractive index for ice, and with a volume lognormal size distribution defined by

$$
\frac{d V(r)}{d \ln r}=C \exp \left(-\frac{1}{2}\left(\frac{\ln r-\ln r_{m}}{\sigma}\right)^{2}\right),
$$

where $r_{m}$ is the mode radius, and $\sigma$ is the log standard deviation of the size distribution. $\sigma=$ ln 1.5 is assumed in our model calculations, because the results are not strongly affected by this assumption for the same effective particle radius $r_{e}=r_{m} \exp \left(0.5 \sigma^{2}\right)$. We will argue the effect of non-sphericity of cirrus particles in section 5 .

\subsection{A three-channel retrieval method}

In the preceding section we discussed the cloud parameter retrieval assuming a single cloud layer. In the real situation, however, there are other parameters to take into account in the retrieval, such as cloud fraction, cloud top temperature, and cloud altitude. Figure 3 shows BTD curves versus BT at $10.8 \mu \mathrm{m}, \mathrm{BT}_{11}$, 


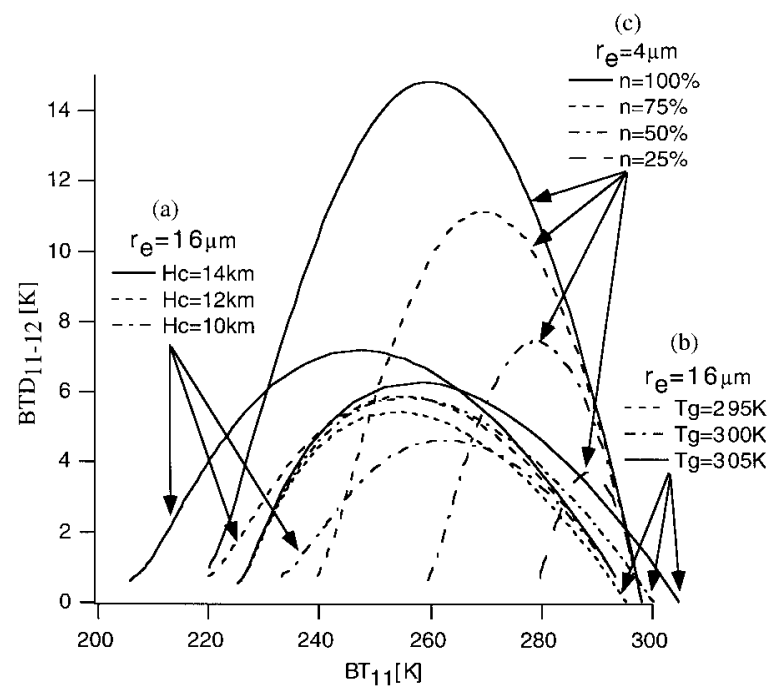

Fig. 3. Brightness temperature difference $\mathrm{BTD}_{11-12}$ versus brightness temperature $\mathrm{BT}_{11}$ for (a) cloud top height of $H_{c}=14,12$, and $10 \mathrm{~km}$, with $r_{e}=16$ $\mu \mathrm{m}$, surface temperature of $T_{g}=295 \mathrm{~K}$, and cloud amount of $n=100 \%$, (b) surface temperature of $T_{g}=295,300$, and $305 \mathrm{~K}$, with $r_{e}=16 \mu \mathrm{m}, n=100 \%$, and $H_{c}=12 \mathrm{~km}$, and (c) cloud amount of $n=100,75,50,25 \%$, with $r_{e}=4 \mu \mathrm{m}$, $T_{g}=295 \mathrm{~K}$, and $H_{c}=11 \mathrm{~km}$.

which were calculated for a variety of cloud top heights $\left(H_{c}=14,12\right.$ and $\left.10 \mathrm{~km}\right)$, surface temperatures $(295,300$ and $305 \mathrm{~K})$, and cloud amounts (100, 75, 50 and 25\%). The right foot of the BTD curves depends almost uniquely on the surface temperature change, whereas the left foot and the amplitude of the BTD curve depend on various parameters. Giraud et al. (1997) showed similar figures, and noted that cirrus clouds have heterogeneity formed by various combinations of the situations as shown in Fig. 3 in the observed scene of satellites. Especially the cloud amount effect is a serious problem in the retrieval of the cloud microphysical properties, i.e., the cloud optical thickness and effective particle radius.

When the cirrus cloud is optically very thick, the $\mathrm{BT}_{11}$ may be the cloud top temperature. If the BTD is small enough and BT is low enough, BT will be thought as the cirrus cloud top temperature (see Fig. 1). However, it is difficult to settle a threshold value successfully, because the left feet of the curves are dispersed with

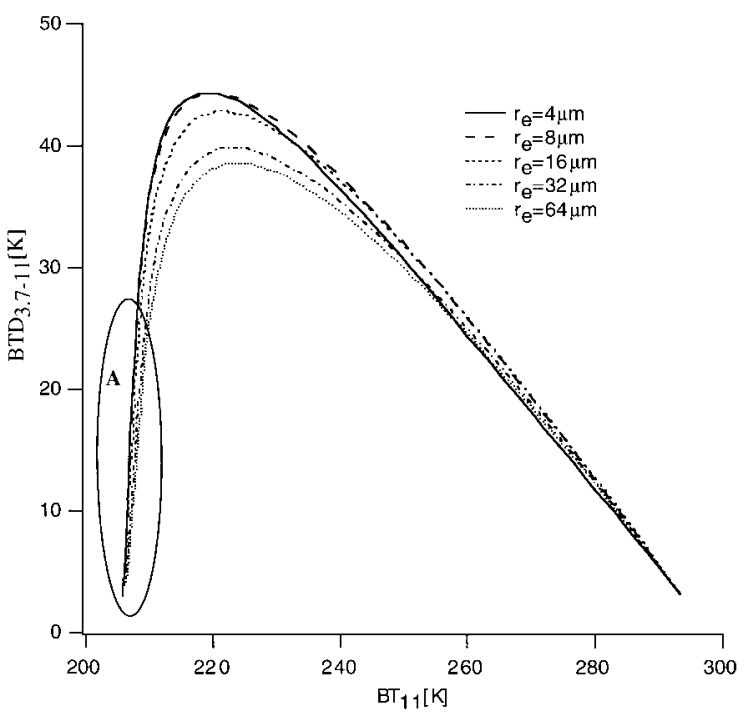

Fig. 4. $\mathrm{BTD}_{3.7-11}$ as a function of $\mathrm{BT}_{11}$ for various effective particle radii.

their radii, such as $\mathrm{BT}_{11}$ of $0.3 \mathrm{~K}$ for $r_{e}=64 \mu \mathrm{m}$ and $2 \mathrm{~K}$ for $r_{e}=4 \mu \mathrm{m}$. This dispersion is significantly large to induce a large error in the retrieval. For instance, if we chose $2 \mathrm{~K}$ as a threshold of the BTD value in Fig. 1, there can be about $10 \mathrm{~K}$ error between the effective radius of $64 \mu \mathrm{m}$ and $4 \mu \mathrm{m}$. To acquire the cloud top temperature more accurately, we need another independent constraint. This study uses BTD curves between wavelength 3.7 , and 10.8 $\mu \mathrm{m}, \mathrm{BTD}_{3.7-11}$. These $\mathrm{BTD}_{3.7-11}$ curves are shown in Fig. 4, where the BTD curves are calculated as a function of the corresponding $\mathrm{BT}_{11}$ in nighttime, because the radiance at $3.7 \mu \mathrm{m}$ contains the solar radiation reflected by the ground surface, sea surface, and cloud layer in daytime. The $\mathrm{BTD}_{3.7-11}$ curves in Fig. 4 have larger amplitudes than the $\mathrm{BTD}_{11-12}$ curves as shown in Fig. 1, and also have the wider $\mathrm{BT}_{11}$ range of linear dependence on BTD with a sharp cut near the cloud top temperature. Therefore the cloud top temperature can be determined from the curves with better accuracy than from the $\mathrm{BTD}_{11-12}$ curves only.

The effect of the cloud amount in the subpixel is troublesome to be accounted in determination of the cloud microphysical properties. An analysis of pixels of the fractional cloud cover will overestimate the particle radius if we do not correct the cloud amount effect. Under 
the situation that there is no good method of obtaining the sub-pixel cloud fraction, we avail in this study the envelope of BTD curves formed by pixels in each segmented box, because the pixels aligned on the envelope are considered to have the largest sub-pixel cloud fraction among those of other pixels if the microphysical properties of clouds are the same as understood by curves with different cloud fractions shown in Fig. 3. We assume the $100 \%$ sub-pixel cloud fraction for analyzing the pixels on the envelope. Although most of the cirrus cloud pixels are optically thick enough to determine the cloud top temperature, there are occasionally pixels with insufficient optical thickness around the border of cirrus clouds to determine the cloud top temperature. This method of utilizing the envelope of $\mathrm{BTD}_{3.7-11}$ curves also enable us to fix the cloud top temperature of the target region by fitting the satellite data around the left foot to the sharp cut region $(\mathrm{A})$ of $\mathrm{BTD}_{3.7-11}$.

We have described the single cirrus layer case so far, but in the real situation there are a lot of cases with underlying clouds over high altitude cirrus clouds to be analyzed. Figure 5 shows an example of the $\mathrm{BTD}_{11-12}$ curves under the condition of overlapped clouds such that a cirrus cloud layer exists above a low level water cloud layer, with a cloud top temperature of $250 \mathrm{~K}$ and various optical thicknesses. We assumed that the lower cloud consists of water droplets with an effective radius of $8 \mu \mathrm{m}$, and the upper cirrus layer consists of ice particles with an effective radius of $10 \mu \mathrm{m}$. The cirrus cloud is placed at an altitude of $12 \mathrm{~km}$. The BTD $_{11-12}$ curves in Fig. 5 depend on the lower cloud condition, such that the right foot of the $\mathrm{BTD}_{11-12}$ of the cirrus cloud stand on the $\mathrm{BTD}_{11-12}$ value of the overlapped low cloud, which depends on the optical thickness of the layer. The amplitude of the $\mathrm{BTD}_{11-12}$ curve of the cirrus cloud also depends on the low cloud condition. If we do not consider this situation, we may overestimate the effective radius and optical thickness of the cirrus cloud. In this analysis, we assumed that the low cloud is optically thick enough to be regarded as an underlying surface similar to the sea surface with a low temperature. It was mentioned above that the $\mathrm{BTD}_{3.7-11}$ curves have similar inclinations to each other near the right feet of the (a)

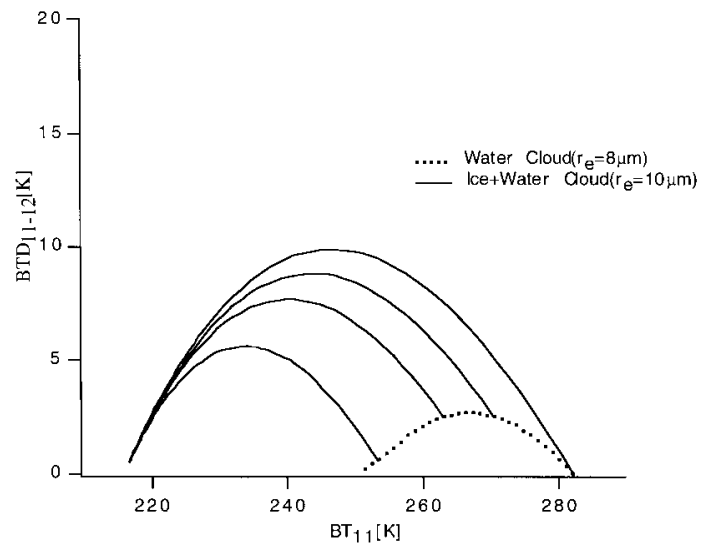

(b)

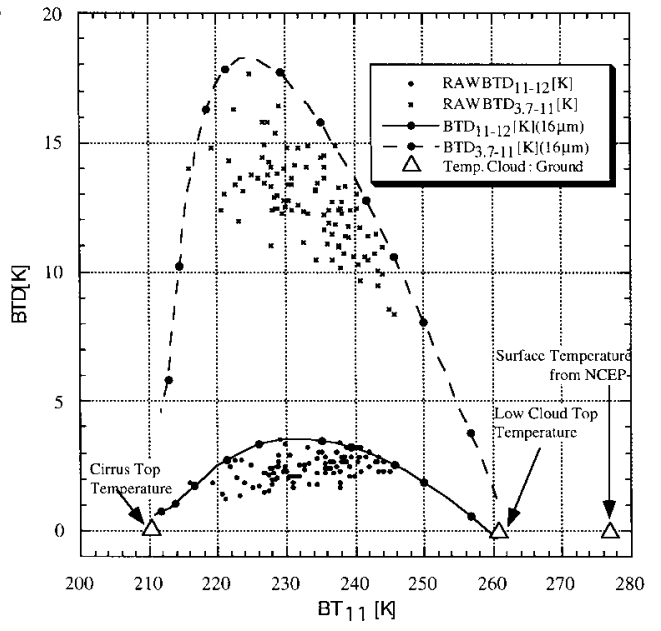

Fig. 5. (a) $\mathrm{BTD}_{11-12}$ versus $\mathrm{BT}_{11}$ curves of two layer cloud systems with a cirrus and an underlying low level water cloud. The dotted line represents the BTD curve of the low level water cloud alone without the cirrus cloud. (b) An example of satellite data plot of $\mathrm{BTD}_{11-12}$ versus $\mathrm{BT}_{11}$ chart. Curves of $\mathrm{BTD}_{11-12}$ and $\mathrm{BTD}_{3.7-11}$ with $r_{e}=16$ $\mu \mathrm{m}$ are also shown with the data. The surface temperature from NCEP, the retrieved cirrus cloud top temperature, and the retrieved underlying cloud temperature are shown by open triangles at $221 \mathrm{~K}, 278 \mathrm{~K}$, and $261 \mathrm{~K}$, respectively.

curves without a large dependence on the effective radii, so that the cloud top temperature of the low cloud lying below the cirrus clouds is determined by using the inclination near the cloud top temperature, similar to the cirrus cloud top temperature case. These two adjust- 


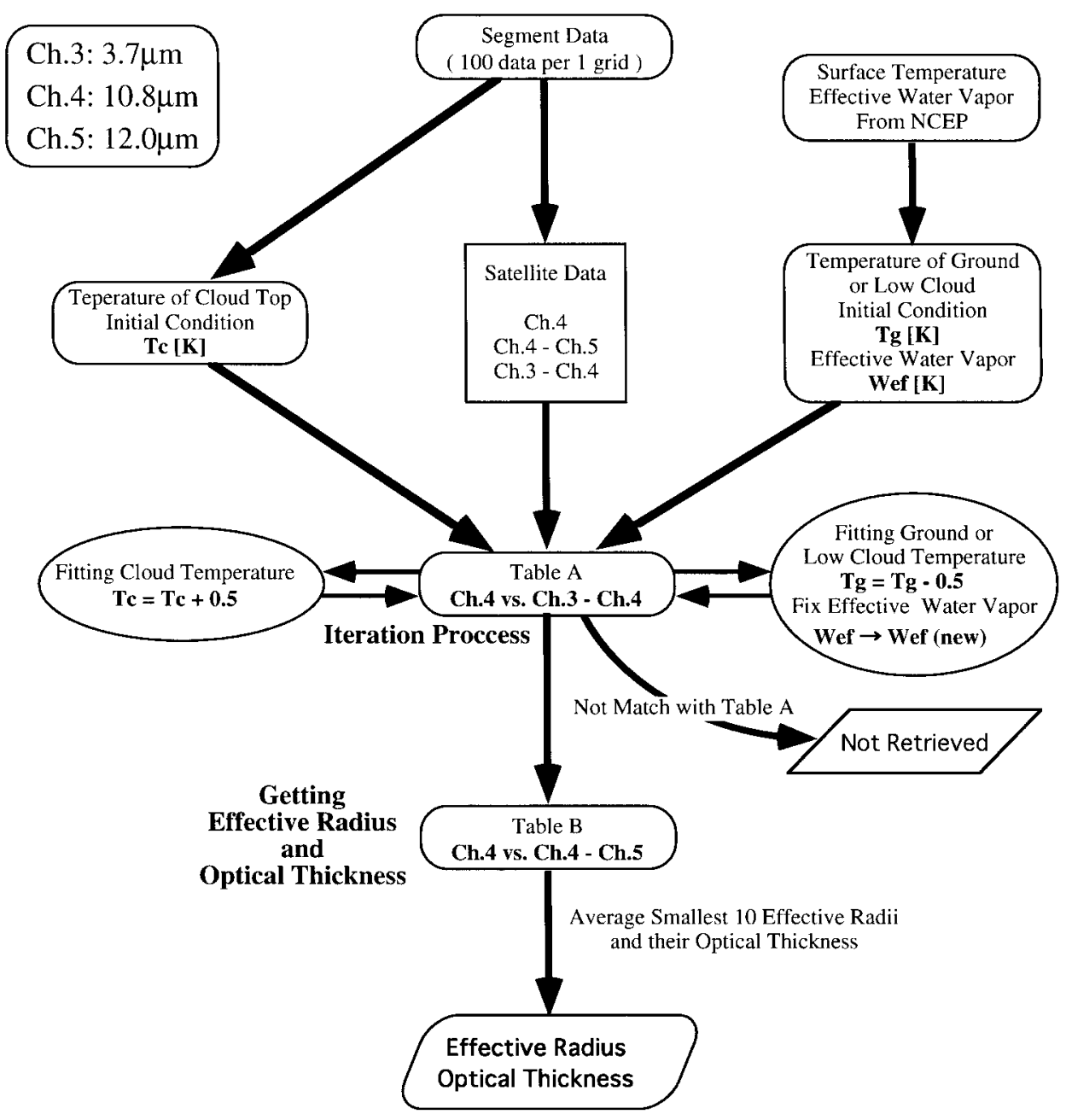

Fig. 6. The flow of the three-channel method. Table A consists of values of $\mathrm{BTD}_{3.7-11}$ versus $\mathrm{BT}_{11}$ and Table $\mathrm{B}$ consists of values of $\mathrm{BTD}_{11-12}$ versus $\mathrm{BT}_{11}$.

ments for the cirrus top temperature and for the low cloud top temperature are illustrated in Fig. 5. We compare the theoretical radiances constructed from the lookup table with the scatter plot of satellite data iteratively by changing cloud top and surface temperatures from their initial values until the inclination of the BTD curves and the envelope near the feet of the curves agree with each other.

The flow of the present three-channel method is shown in Fig. 6. Pixels of cirrus are first assumed tentatively by a condition that the minimum $\mathrm{BT}_{11}$ is lower than $270 \mathrm{~K}$. At this time they are not settled as cirrus pixels. This ambiguous classification is used not to abandon thin cirrus clouds. Secondly we get the corresponding temperature and water vapor profiles from a reference climate data to set the initial surface temperature $T_{g}^{*}$, and column effective water vapor $w_{e}$, following Kawamoto (2001) for each $0.5^{\circ} \times 0.5^{\circ}$ segment area. We also assume an initial cloud top temperature $T_{c}^{*}$ which is low enough as compared with the actual cloud top temperature. Thirdly the actual cloud top temperature $T_{c}$ and surface temperature $T_{g}$ are retrieved by the iteration process, with the temperature adjustment explained in Fig. 6 using the lookup table-A consists of the calculated data sets of $\mathrm{BTD}_{3.7-11}$ versus $\mathrm{BT}_{11}$. In this process $w_{e}$ between the cirrus cloud and the low 
cloud is recalculated with the updated values of the cloud top temperatures. The retrieval is not attempted in the segment box when this process does not work suitably such that the dispersion of the data in the segment box is insufficient or that the temporal cloud top temperature is not settled in the iteration process. Finally, the data with $T_{g}, T_{c}$, and $w_{e}$ are compared with the lookup table-B, which consists of the data sets of $\mathrm{BTD}_{11-12}$ versus $\mathrm{BT}_{11}$, to detect the envelope of the scatter plot. We calculate $r_{e}$ and $\tau_{c}$ for all data scattered in the target segment box within the area for retrieval shown in Fig. 1 to ward off error caused by congested look up table data and get the averages of smaller ten effective radii and their optical thickness that correspond to the envelope of the scattered data in the segmented grid to avoid an imperfect cloud coverage as discussed in the first part of this section.

We note here that the relation between $\mathrm{BTD}_{3.7-11}$ and $\mathrm{BT}_{11}$ was used to retrieve the radiative parameters of cirrus clouds such as by Ou et al. (1993; 1995), but we adopt the other relation between $\mathrm{BTD}_{11-12}$ and $\mathrm{BT}_{11}$ instead to retrieve the parameters, because the first one has dual solution for smaller radii, and it makes the retrieval process more difficult especially for global analysis.

As the result, we can retrieve the effective radius, optical thickness, and cloud top temperature of cirrus clouds, and the low cloud top temperature under the cirrus cloud in two layer cases.

The lookup table-A and -B are constructed with theoretical radiances at gridded values of surface temperature $T_{g}$, cloud top temperature $T_{c}$, equivalent water vapor amount $w_{e}$ above the ground surface or the underlying low level cloud layer, and satellite zenith angle $\theta$, as listed in Table 1. We assume in the lookup tables $100 \%$ cloudiness and the geometrical thickness of cirrus cloud as $2 \mathrm{~km}$. The effects of this assumption of the geometrical thickness will be discussed in section 5. National Centers for Environmental Prediction-National Center for Atmospheric Research (NCEP-NCAR) reanalysis data are used for a reference climate data of vertical temperature, pressure, and humidity profiles to calculate $w_{e}$.

The accuracy of retrievals by this algorithm depends remarkably on the accuracy of the
Table 1. Grid system for Lookup Tables.

\begin{tabular}{lc}
\hline Parameter & Grid \\
\hline Effective Radius & $4,8,16,32,64 \mu \mathrm{m}$ \\
Optical Thickness & $0 \sim 2$ (increase of 0.2$)$ \\
& $2 \sim 5(0.5) ; 5 \sim 20$ \\
& (gradually) \\
Low Surface & $310 \sim 230 \mathrm{~K}$ (decrease \\
Temperature & of $5 \mathrm{~K}$ ) \\
Cloud Top Altitude & $4 \sim 18 \mathrm{~km}$ (increase of \\
& $2 \mathrm{~km}$ ) \\
Effective Water Vapor & $7 \mathrm{kinds}$ \\
Satellite Zenith Angle & $0,30,60$ degree \\
\hline
\end{tabular}

cloud top temperature and low surface temperature, and on the nonlinear dependence of each effective radius on $\mathrm{BTD}_{11-12}$. Although it is difficult to assess the accuracy in each application of the method to real data, there can be about $10 \%$ error by the cloud temperature error of $10 \mathrm{~K}$ when the effective radius is $16 \mu \mathrm{m}$ with moderate optical thickness in the tropics.

\section{Global analyses}

We apply the present retrieval method to AVHRR data. Segmented data sets of AVHRR radiances are prepared for an efficient analysis on global scale, segmenting the AVHRR Global Area Coverage (GAC) data into $0.5^{\circ} \times 0.5^{\circ}$ boxes in the region of the $-60^{\circ}$ to $+60^{\circ}$ latitudinal belt. Each segment box keeps a hundred pixel data for each channel, but discards the information of satellite angles and positions, except those of the center pixel of the grid for saving computer resources of the storage system. Segment data sets are made everyday for four months (i.e., January, April, July, and October) in the analysis period from 1986 through 1994. And, we have performed four-month daily global analysis for every segmented data of those nearly 9 years. Daily results are further averaged to make monthly and spatially $2.5^{\circ} \times 2.5^{\circ}$ gridded data sets.

Figures 7(a), (b), and (c) show averaged fourmonth results of $r_{e}, \tau_{c}$, and $T_{c}$, during the nine years, respectively, and panels 1), 2), 3), and 4) correspond to January, April, July, and October, respectively. The black colored grids in these pictures mean this analysis did not rec- 

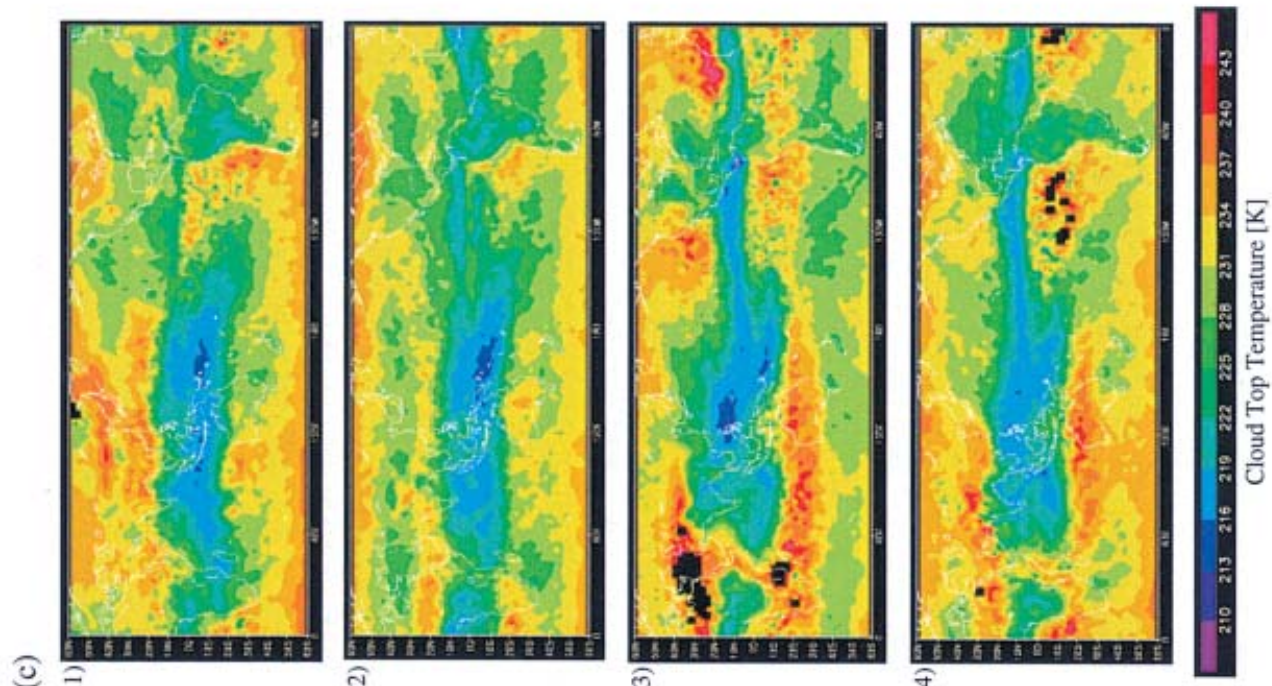

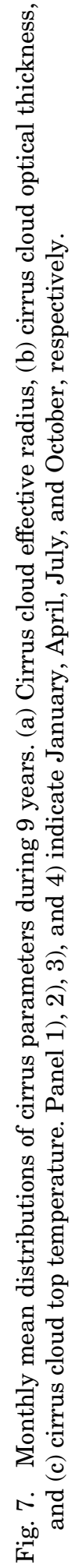

(])
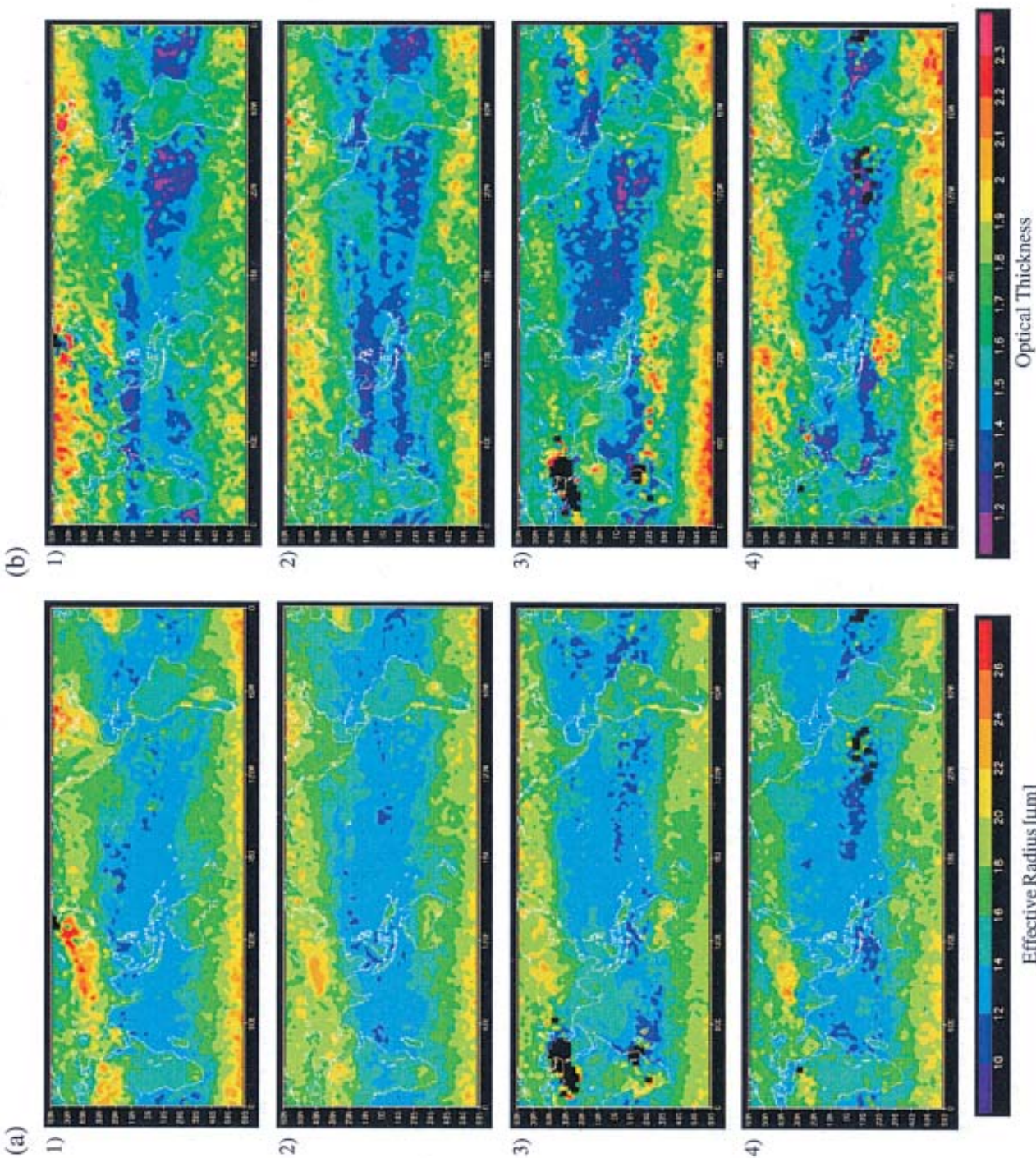

f 
ognize the existence of cirrus clouds in these grids, and it is thought that in these areas cirrus clouds are very thin or do not exist. Figures 8(a), (b), and (c) show the zonal averaged $r_{e}, \tau_{c}$, and $T_{c}$, for the four months respectively. The zonal distributions of $r_{e}$ in Figs. 7 and 8 display the latitudinal dependency that the effective radius of cirrus clouds in the tropical region is smaller than that of mid- and high-latitudinal regions. This contrast is thought to be caused by difference in the cirrus particle formation process in these regions. Cirrus clouds in the tropics usually flow out from the top of deep convective cloud systems near the tropopause, and their particles grow in high altitude with low temperature and humidity, and cirrus cloud particles associated with the low pressure system grow with high temperature and humidity in mid- and high-latitudes. Our finding is consistent with the relation of particle size and temperature proposed by Heymsfield and Platt (1984). Figure 8(a) shows that $r_{e} \approx 13 \sim 14$ $\mu \mathrm{m}$ in the tropical region, and they have a small seasonal variation with smaller values in April and October, and larger in January and June. Such a particle radius distribution is consistently understood by the cloud top temperature distribution as shown in Figs. 7(c) and 8(c). Very low cloud top temperature (about $215 \mathrm{~K}$ ) appears in the West Pacific Ocean near the east region of New Guinea in January and April, and around the Philippine Islands in July. Low cloud top temperatures appear in the other equatorial regions from the west to the center of the Pacific Ocean have low temperature (about $220 \mathrm{~K}$ ) all through the year, and also in the regions around Central Africa. The Amazon region has a cloud top temperature as low as about $220 \mathrm{~K}$, except in the dry season in July. From mid- to high-latitudes, $r_{e}$ increases from 14 to $19 \mu \mathrm{m}$. There is also a seasonal variation of $r_{e}$ in mid-latitudes of the northern hemisphere similar to the tropical region with larger amplitude, whereas there is little variation in mid-latitudes of the southern hemisphere. This difference looks caused by the land/ocean area difference. This tendency is clearly seen by the striking seasonal fluctuation of $r_{e}$ around the continent of Asia and North America in Fig. 7(a), although this can be an artifact due to a large retrieval error caused by the warm cloud top temperature and very cold ground temper- (a)

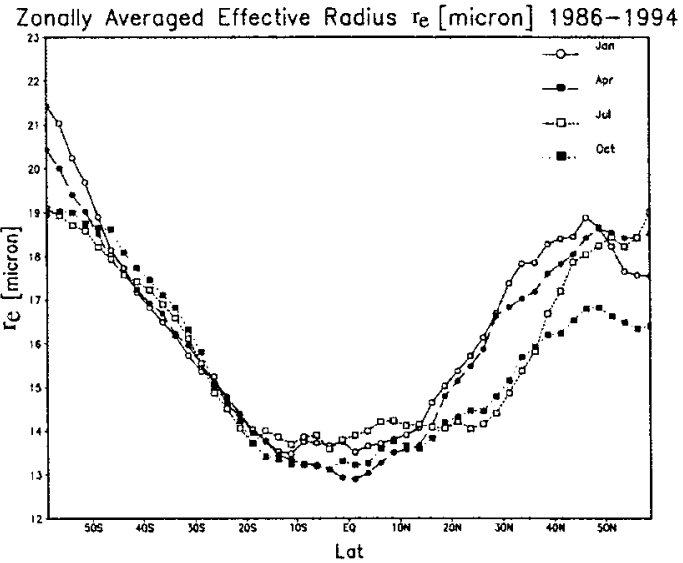

(b)

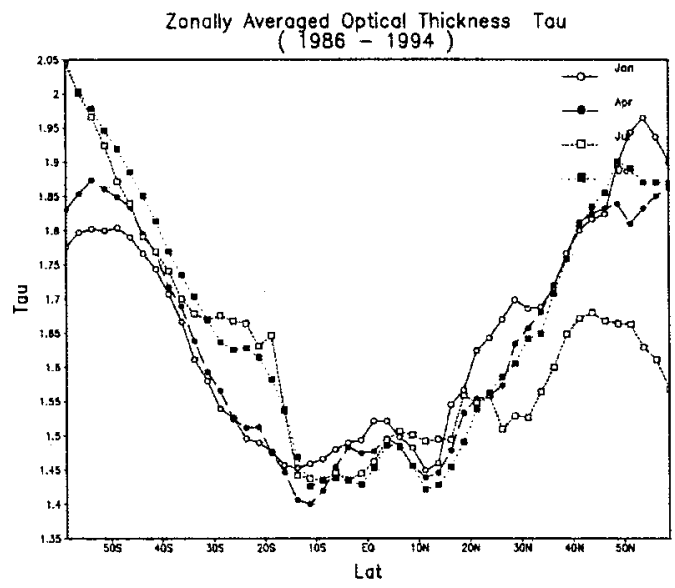

(c)

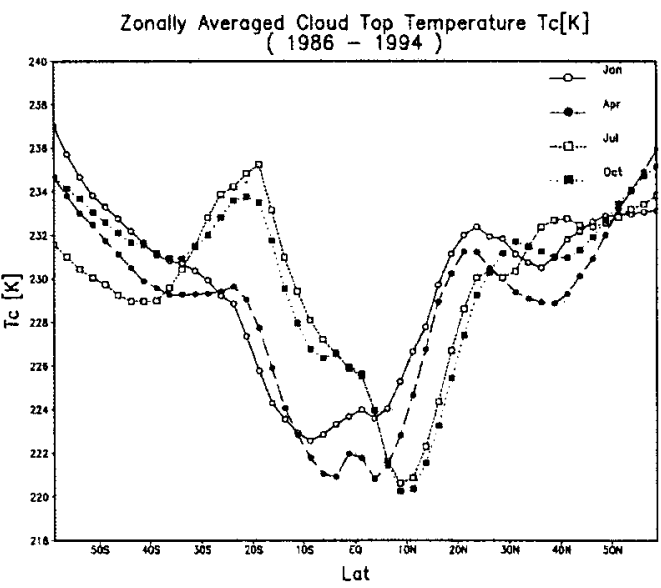

Fig. 8. Zonal mean values of the cirrus parameters, $r_{e}, \tau_{c}$, and $T_{c}$, as a function of the latitude for 9 year averages of monthly mean values for January, April, July, and October. 
ature when amplitudes of BTD curves becomes small.

It is found in Figs. 7(b) and 8(b) that the latitudinal dependence of the optical thickness $\tau_{c}$ varies from $\tau_{c} \approx 1.45$ in the tropics to about 1.90 in high-latitudes. Similar to $r_{e}$, a seasonal variation in $\tau_{c}$ is also seen in Figs. 7(b) and 8(b), with larger values around the high latitudinal regions of the winter hemisphere, and with smaller values in the summer hemisphere. Although the deep cumulonimbus clouds with very thick optical thickness arise throughout the year in the tropical region, cirrus clouds that spread from the top of the deep convective clouds have very small optical thickness (1.0 1.7), whereas cirrus clouds associated with the low pressures have large optical thickness.

Figures 9(a), (b), and (c) show time series of $r_{e}, \tau_{c}$, and $T_{c}$ during 9 years, respectively, where the global mean, tropical mean, northern hemisphere mean, and southern hemisphere mean values are plotted. We used the data of NOAA-9 from 1986 to 1988, and the data of NOAA-11 from 1989 to 1994 . The time series of $r_{e}$ has values around 12 16 $\mu \mathrm{m}$ in the tropical regions, values around $14 \sim 20 \mu \mathrm{m}$ in the northern hemisphere, and values around $14 \sim 20 \mu \mathrm{m}$ in the southern hemisphere, reflecting the characteristic distribution in Figs. 7 and 8. There seems to be a difference between the retrieved values from the data of NOAA-9 and NOAA-11 (switched in the end of 1988) caused by the radiometric calibration error of radiances for the imagers.

In Fig. 9(a), $r_{e}$ became large after the eruption of Mt. Pinatubo, and reached its maximum in July in the tropics, in October in the southern hemisphere, and in January in the northern hemisphere. The Volcano Pinatubo in Luzon-Island, the Philippines, erupted in June 1991. It is thought to be the largest scale eruption in the 20th century. Its volcanic ashes reached the altitude of $30 \mathrm{~km}$ across the tropopause (Bluth et al. 1992), so that there is a possibility that the volcanic ashes changed the properties of cirrus clouds. It is also pointed out that cirrus clouds have sensitivity to the size and the density of nuclei (Sassen and Dodd 1989), and that the aftermath of the eruption of Mt. Pinatubo has continued for almost two years (Anderson and Saxena 1996), and af- (a)

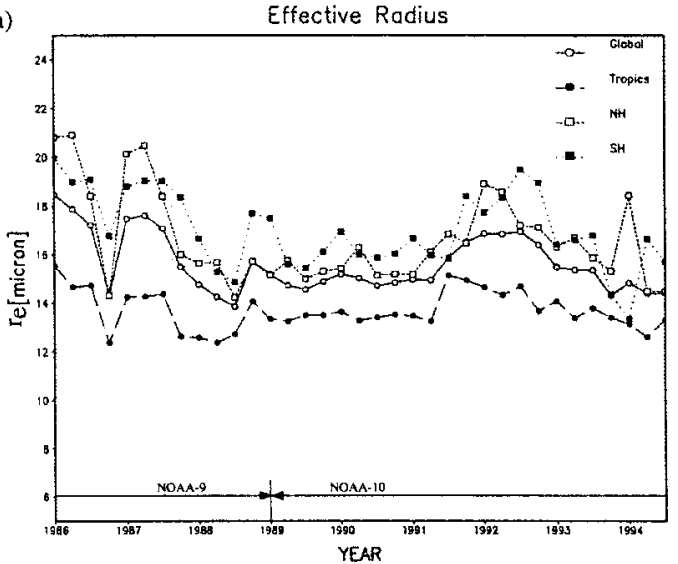

(b)

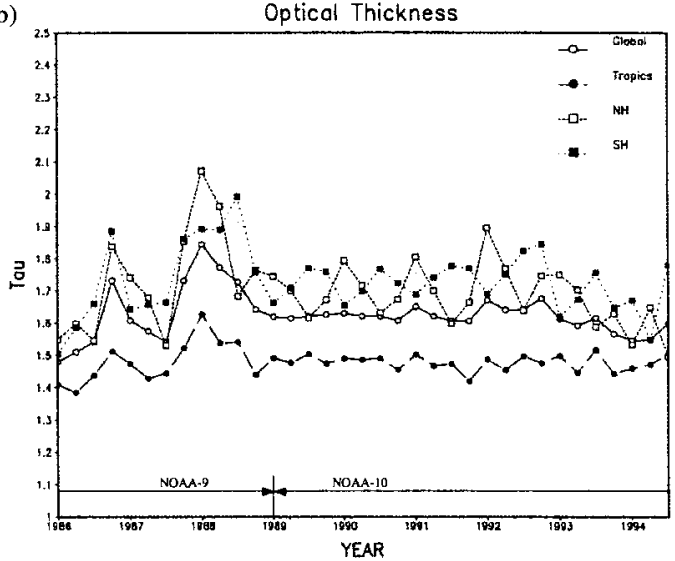

(c)

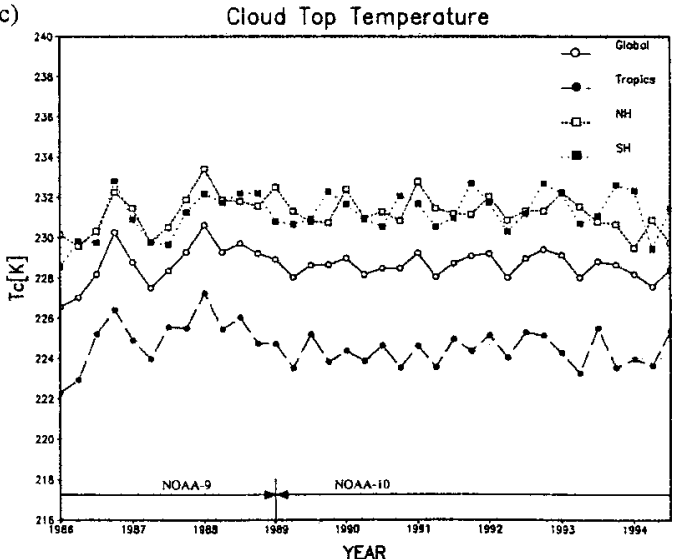

Fig. 9. Time series of the cirrus parameters. Global mean, hemispherical means $(60 \mathrm{~N}-20 \mathrm{~N}: \mathrm{NH}, 60 \mathrm{~S}-20 \mathrm{~S}: \mathrm{SH})$, and tropical areal mean $(20 \mathrm{~N}-20 \mathrm{~S})$ are shown for $r_{e}, \tau_{c}$, and $T_{c}$. 
fected cirrus clouds through large cloud condensation nuclei of volcanic origin (Sassen 1992). Volcanic ashes itself decrease the BTD in the infrared region (Prata 1989) causing an overestimation in the effective radius, while volcanic ashes act as ice condensation nuclei to decrease the effective radius of the cirrus clouds. It is, therefore, difficult to mention if the increasing trend of $r_{e}$ after the volcanic eruption was caused by the volcanic ash effect without validation data.

The optical thickness of cirrus clouds shown in Fig. 9(b) looks relatively stable after 1989, but it seems to have discontinuity between the data from NOAA-9 and NOAA-11 similar to the case in $r_{e}$. In the tropics, $\tau_{c}$ is 1.4 1.6, and in the northern and the southern hemispheres, it fluctuates between 1.5 and 2.0 with a seasonal change taking large values in the winter hemisphere and small values in the summer hemisphere. But $\tau_{c}$ does not have a clear trend, suggesting that the optical thickness of the volcanic ashes was thin and ice nucleation effect to the optical thickness was small. Stowe et al. (1992) shows the Pinatubo aerosol optical thickness reaches the maximum around 0.6 in the tropical region but decreased rapidly within two years after the eruption. Asano et al. (1993) observed the optical thickness of $0.14 \sim 0.19$ at $680 \mathrm{~nm}$ at Tsukuba in Japan in January, 1992.

$T_{c}$ ranges between 222 and $227 \mathrm{~K}$ in the tropics, between 230 and $240 \mathrm{~K}$ in the northern and the southern hemisphere. The effects of the volcanic ashes on $T_{c}$ are also not observed similar to the case of $\tau_{c}$.

\section{Comparison with other products}

There is very limited in situ observation of the effective radius of cirrus clouds for validating the present satellite products. But the relations between cirrus ice particle size distribution and cirrus cloud temperature are parameterized to use for modeling studies (Heymsfield and Platt 1984; Kosarev and Mazin 1991; McFarquhar and Heymsfield 1997). Figure 10 shows the relative number of the effective radius of cirrus clouds retrieved by our work (shadowed) and aircraft data by Heymsfield and Platt (1984) arranged by Suzuki et al. (1993) (solid lines) as a function of the cloud top temperature, although these two results do not accord over time nor space with each other. It is

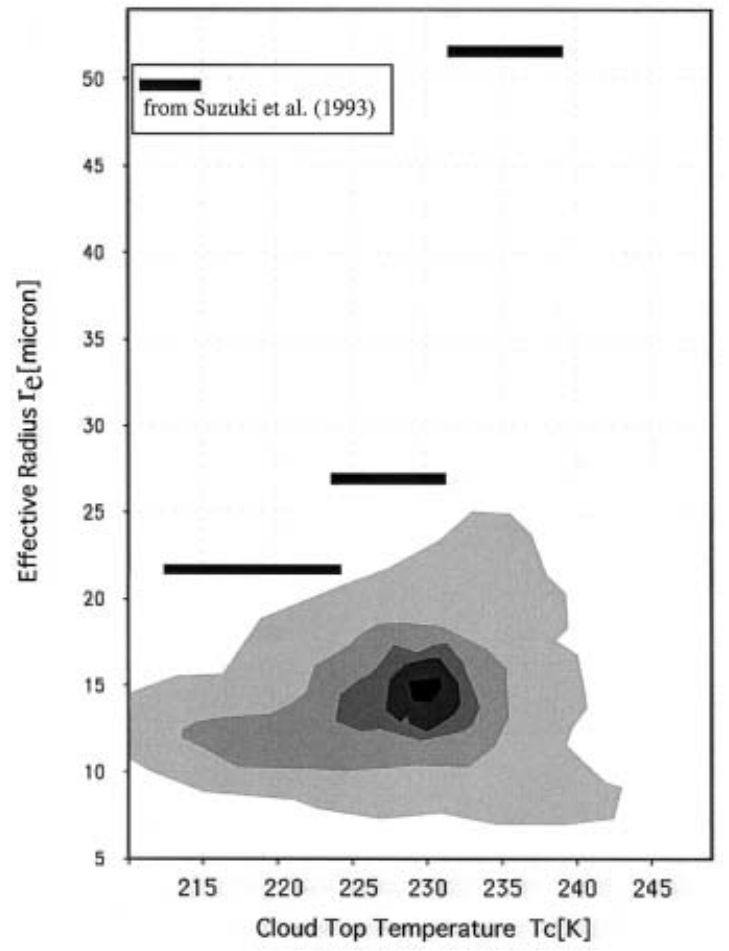

Fig. 10. Dependence of the effective particle radius on the cloud top temperature from the present method (shaded area) and airborne measurements arranged by Suzuki et al. (1993, solid lines). The results from the present method are shown by a relative frequency distribution of occurrence.

found from the figure that the present satellite results are largely underestimated less than the aircraft results, such that $10 \sim 15 \mu \mathrm{m}$ versus $22 \mu \mathrm{m}$ around $220 \mathrm{~K}$, and $10 \sim 20 \mu \mathrm{m}$ versus $60 \mu \mathrm{m}$ at $230 \mathrm{~K}$. In spite of the large discrepancy, the result from the present algorithm has some similarity in the temperature dependence even with the transition occurred around $230 \mathrm{~K}$ due to the transformation of the shape of ice particles from column to bullet rosettes type. There are several reasons for this discrepancy. The airborne measurements may be biased because the upper regions of cirrus clouds are not accessible to aircraft, and measurements of cirrus clouds in the tropics are especially difficult. There are reports that pointed out that the probes used in airborne measurements tend to loose the sensitivity to smaller ice particles (Gardiner and Hallett 1985; Gayet et al. 1996; 
Heymsfield and McFarquhar 1996), although the probes have been improved to detect ice particles with tens of micron size (Heymsfield and Miloshevich 1995). Baumgardner and Korolev (1997) also noted that uncertainty in the sampling volume at small crystal sizes and high air speeds cause errors. Reported particle size distributions show a large variety over crystal sizes from 1 to $8000 \mu \mathrm{m}$ (Dowling and Radke 1990). In recent airborne measurements, Arnott et al. (1994) and Strom et al. (1997) found a high concentration of small ice particles, and Knollenberg et al. (1993), Heymsfield and McFarquhar (1996), and Heymsfield (1986) observed small crystals dominated in the high altitude layer of cirrus clouds. Okamoto et al. (2003) reported that the effective radius derived by their cloud radar and lidar synergy observation decreases with height in the cirrus cloud layer. On the other hand, our algorithm uses the envelope of scattered data that corresponds to the smallest particles when the scatter is caused by a variety of cloudiness and an inhomogeneity of optical thickness, not by particle size changes. In addition, when the cirrus cloud has super cooled small water particles in its lower layer, the analysis should seriously underestimate their effective radius, because the super cooled small particles also make the brightness temperature differences similar to the case with small ice crystals. For example, when all the raw data as in Fig. 5(b) are analyzed with neither a cloudiness nor an inhomogeneity of optical thickness, their effective radii are estimated about from 16 64 $\mu \mathrm{m}$ instead of $16 \mu \mathrm{m}$ from the envelope analysis. Heymsfield and Platt (1984) referred to the temperature dependence of the ice particle size, but Atlas et al. (1995) gave their opinion that the temperature dependence proposed by Heymsfield and Platt (1984) is not reliable for the cirrus clouds whose temperature is warmer than $230 \mathrm{~K}$, and for the convective cirrus clouds. Heymsfield and Miloshevich (2003) reported that the variability of microphysical properties in cirrus clouds was larger in the lower parts of cirrus clouds than in the upper parts by introducing the shapesensitive parameter "area ratio" and also noted the importance of considering the vertical variability of microphysical properties such as the aggregation process in each part. Although we need more careful validation of the present algorithm in future, it should be pointed out that the effective radius from our method was obtained by using infrared and near-infrared channel radiances, so that the result should be regarded as effective in estimating the radiative budget. It was reported that the vertical water transport is mainly governed by large particles, while small particles mainly affect the radiative properties of clouds (Beck et al. 1996; Jensen et al. 1994; Arnott et al. 1994).

We have compared our results with the D2 global data sets (monthly mean) produced by International Satellite Cloud Climatology Project (ISCCP) (Schiffer and Rossow 1985; Rossow and Schiffer 1991; Rossow et al. 1996), which are the products of the global cloud parameter distributions (e.g. the cloudiness of all and each kind of clouds, the optical thickness) including cirrus clouds for a long period (Stowe et al. 1989; Rossow and Schiffer 1991; Wylie et al. 1994). It should be noted that ISCCP D2 data is a composite of daytime and nighttime results, while our results consist of the nighttime analysis.

Figures 11(a) and (b) show the monthly mean cloud top temperature and the optical thickness of cirrus in July 1992 produced by ISCCP (D2data), respectively. It is found that the value of the ISCCP temperature and its distribution are largely different from the present result in Fig. 7. One significant difference is that the regions with a very low temperature cirrus in D2-data, $T_{c} \approx 200 \mathrm{~K}$, over the region from Amazon to the Atlantic Ocean, over the Mediterranean Ocean, and over South Africa, tend to correspond to the regions without cirrus clouds in our product as shown in Fig. 7 3). Another difference is the high land and ocean contrast of the cirrus cloud top temperature in the D2-data set, i.e., low over land and high over ocean. The present result in Fig. 7 does not have such discontinuity, which looks more realistic. It was also reported that the use of multi-geostationary satellites causes systematic discontinuities among the areas observed by the satellites. Table 2 compares the cloud top temperatures between our results and ISCCP products. The table shows our results are lower than ISCCP about 5 20 $\mathrm{K}$. Wang et al. (1996) studied the vertical profile of the cirrus from the observation of Stratospheric Aerosol and Gas Experiment II (SAGE II) (Mauldin et al. 1985; McCormick 1987), and 


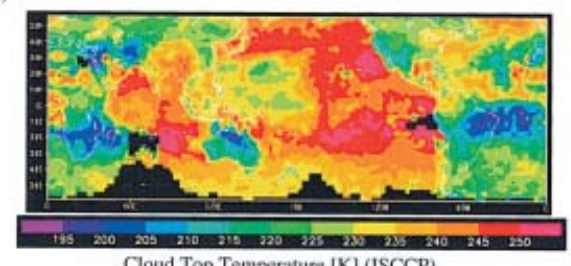

Cloud Top Temperature [K] (ISCCP)

(b)

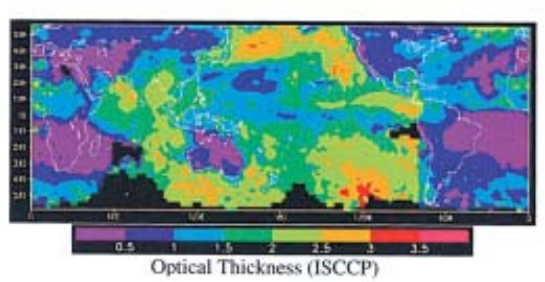

(c)

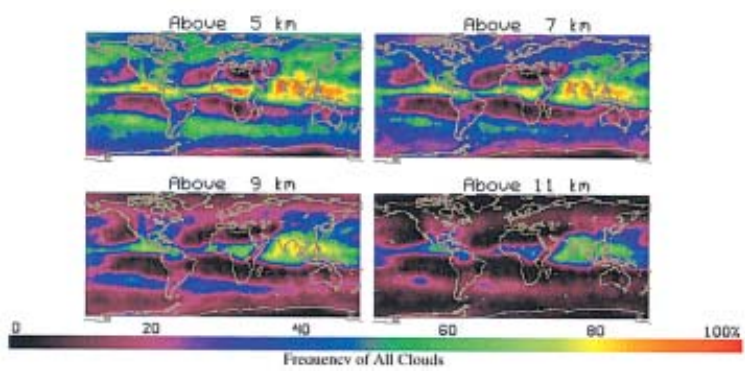

Fig. 11. Monthly mean distribution of the cloud top temperature (a) and optical thickness (b) from ISCCP D2 data in July 1992, and frequency distributions of all clouds obtained by HIRS from ' 89 to '95 (courtesy of Wylie).

Table 2. Comparison of the cloud top temperature with ISCCP D2-data.

\begin{tabular}{lcc}
\hline Region & $T_{c}[\mathrm{~K}]$ & $T_{c}[\mathrm{~K}]$ \\
(our work) & (D2-data) \\
\hline $\begin{array}{l}\text { Global } \\
\text { Indian Ocean }\end{array}$ & $228 \sim 230$ & $230 \sim 240$ \\
$\begin{array}{l}\text { Philippine \& } \\
\quad \text { Indonesia }\end{array}$ & $215 \sim 225$ & $235 \sim 245$ \\
$\begin{array}{l}\text { Off the Atlantic coast } \\
\quad \text { of New York }\end{array}$ & $225 \sim 235$ & $225 \sim 235$ \\
$\begin{array}{l}\text { Tropics around Africa } \\
\text { Off the Pacific coast } \\
\quad \text { of Mexico }\end{array}$ & $215 \sim 225$ & $220 \sim 235$ \\
& $215 \sim 225$ & $235 \sim 245$ \\
\hline
\end{tabular}

noted that the appearance of cirrus clouds reach a maximum rate of $45 \%$ at an altitude of $15 \mathrm{~km}$ in the tropics, and $20 \%$ at $7 \sim 10 \mathrm{~km}$ in mid- and high-latitudes. Rossow and Schiffer
(1999) noted that although the ISCCP D datasets were revised in terms of the radiance calibrations and the ice cloud microphysics model used in their calculations, there still existed $\sim 4 \mathrm{~K}$ biases for optically thin, high clouds. Figure 11(c) shows the seven years of averaged all clouds frequency in July for the heights of 5, 7, 9, and $11 \mathrm{~km}$ detected by HIRS (High Resolution Infrared Radiation Sounder) $\mathrm{CO}_{2}$ slicing method (Wylie and Menzel 1999). This figure, which almost corresponds to Fig. 7(c)-3), indicates that the high cloud distributions by HIRS have similar patterns to our results. These reports fill a bit of the differences between ISCCP and our results. This bias is considered to be caused by; 1) the compensation coefficient for the nighttime processing, which is the mean difference between the result from visible and infrared channels and the result only from infrared channel constructed in daytime; and, 2) the ratio between the optical thickness in visible channel and that in the infrared channel is fixed without dependence on the effective radius of cirrus particles.

The discontinuity of the optical thickness among the observed areas of the satellites is found in Fig. 11(b) similar to the cloud top temperature case. The ISCCP optical thickness is systematically small over land and large over ocean. Table 3 shows the comparison between ISCCP and our results. The optical thickness in the tropics has similar values in both analyses, but our result shows lower values than those of ISCCP over the Pacific Ocean in mid- and highlatitudes and higher values over the Atlantic Ocean in mid- and high-latitudes. We are apt to

Table 3. Comparison of the cloud optical thickness with ISCCP D2-data.

\begin{tabular}{lcc}
\hline Region & $\tau$ (our work) & $\tau$ (D2-data) \\
\hline $\begin{array}{l}\text { Global } \\
\text { Tropics around the } \\
\quad \text { West Pacific Ocean }\end{array}$ & $1.5 \sim 1.8$ & $1.0 \sim 1.5$ \\
$\begin{array}{l}\text { The Pacific Ocean in } \\
\text { the north of } 30^{\circ} \mathrm{N}\end{array}$ & $1.6 \sim 2.2$ & $1.0 \sim 1.5$ \\
$\begin{array}{l}\text { The Pacific Ocean in } \\
\text { the south of } 30^{\circ} \mathrm{S}\end{array}$ & $1.8 \sim 2.4$ & $2.0 \sim 2.3$ \\
$\begin{array}{l}\text { The Atlantic Ocean } \\
\text { in the south of } 30^{\circ} \mathrm{S}\end{array}$ & $1.8 \sim 2.4$ & $1.0 \sim 2.0$ \\
\hline
\end{tabular}


retrieve the value of the optical thickness in a range of about $1 \sim 2$ due to the characteristics of our algorithms that the retrieval area is restricted to moderate optical thickness as illustrated in Fig. 1.

\section{Discussion and conclusions}

We have assumed the ice particle as spherical, whereas there exist non-spherical particles of various shapes, such as needles, solid thick plates, hollow columns, and bullet rosettes (Knollenberg 1970; Miloshevich and Heymsfield 1997). We had a difficulty in introducing the effect of these various non-spherical particles into the retrievals under the situation that we did not have a good non-spherical particle scattering algorithm for the size parameter range larger than 100. Instead we have tested how much errors are induced by the spherical assumption. Figure 12 illustrates the BTD $_{11-12}$ curves calculated when the Mie phase function is modified to have an enhanced side

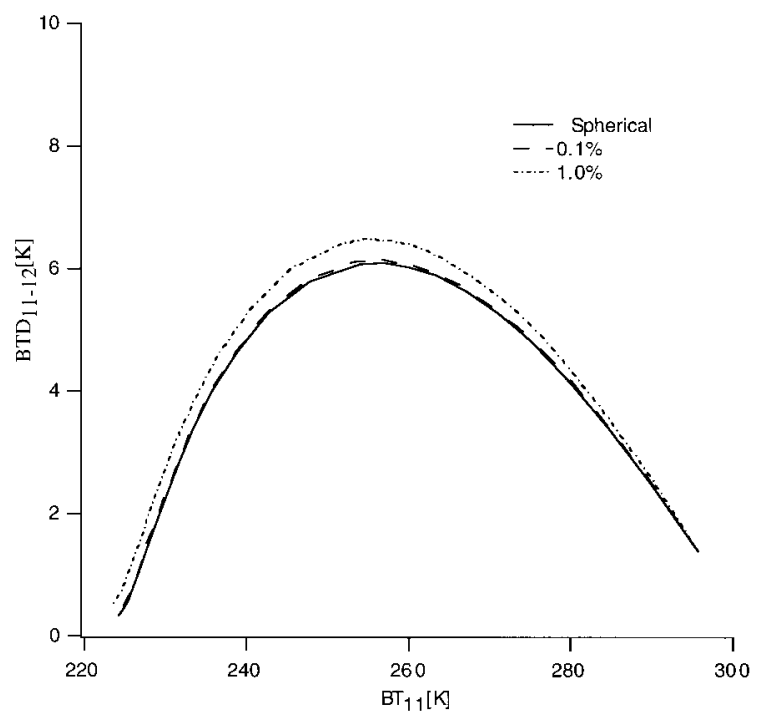

Fig. 12. $\mathrm{BTD}_{11-12}$ versus $\mathrm{BT}_{11}$ plot with various phase functions assumed in the retrieval. The solid line is with the Mie phase function for $16 \mu \mathrm{m}$ effective particle radius. Dashed and dashed-dotted lines are with modified phase functions constructed by adding a constant without angular dependence by a rate of 0.1 and $1.0 \%$ of the total scattering cross section, respectively. scattering by non-spherical particles of random orientation (Liou 1972; Takano and Liou 1993; Macke 1993; Mishchenko et al. 1996). Figure 12 indicates that we should underestimate the effective radius against the actual value by the factor of 0.87 at most with the side scattering enhancement of $1 \%$ of the total scattering. Comparing with Fig. 10, this underestimation cannot explain the main difference between the retrieved results and observed values. Future studies will be needed to fully understand the retrieval differences utilizing the promising non-spherical scattering theories being developed in recent years, such as the Discrete Dipole Approximation (DDA) (e.g., Flatau et al. 1990; Okamoto et al. 1995).

In this study, we have also assumed the geometrical thickness of the cirrus clouds as $2 \mathrm{~km}$. But in fact, the cirrus clouds which have more than $2 \mathrm{~km}$ geometrical thickness often appear around the deep convective cloud system, and which have less than $2 \mathrm{~km}$ also often appear around the outside of extended cirrus clouds. BTD curves are calculated in Fig. 13 with the geometrical thickness of 1,2 and $5 \mathrm{~km}$. The figure shows that we should overestimate the effective radii when the cirrus cloud is geometrically thicker than the assumption, and should underestimate when geometrically thinner. This underestimation is of order of $10 \%$ in the

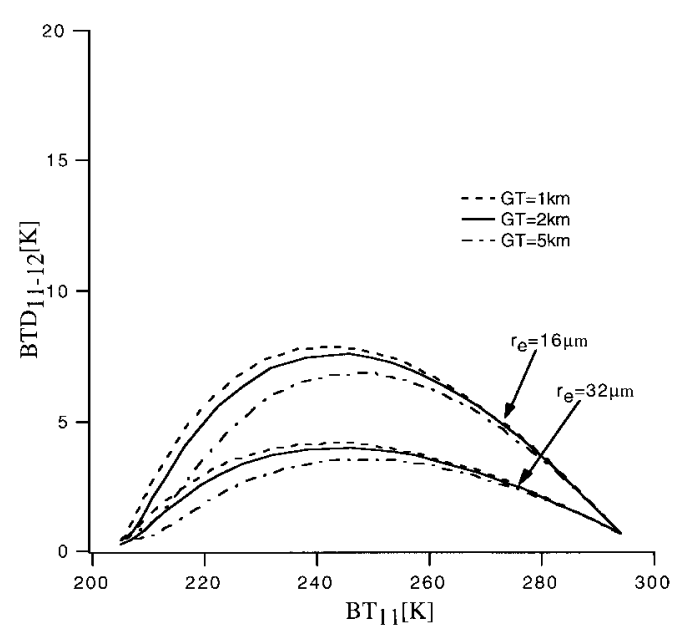

Fig. 13. $\mathrm{BTD}_{11-12}$ versus $\mathrm{BT}_{11}$ plot with various geometrical thicknesses of the cirrus cloud, 1,2 , and $5 \mathrm{~km}$, for two effective particle radii, $r_{e}=16 \mu \mathrm{m}$ and $32 \mu \mathrm{m}$. 
effective radius, and cannot explain the tendency of difference between results of Heymsfield and Platt (1984) arranged by Suzuki et al. (1993) and our results in Fig. 11.

As a summary, that we were able to depict the main features of microphysical structure of the cirrus cloud system on global scale with long-term analysis. It is found that cirrus properties are highly variable depending on time and space, but not in the degree of ISCCP analysis, which tends to show more distinct discontinuities in optical thickness and effective particle radius, especially near the land/ ocean boundary. The microphysical state of cirrus clouds from our analysis has a mode around $r_{e}=14 \mu \mathrm{m}, \tau_{c}=1.6$, and $T_{c}=230 \mathrm{~K}$. Compared with the aircraft observation and ISCCP analysis, these parameters have difference of $\Delta r_{e}=-10 \sim-15 \mu \mathrm{m}, \Delta \tau_{c}=-0.8 \sim+0.8$, and $\Delta T_{c}=-5 \sim-20 \mathrm{~K}$. Our values of $r_{e}$ should be smallest, because of selecting pixels for analysis located on the largest BTD values in each $0.5^{\circ} \times 0.5^{\circ}$ longitude-latitude segment. The degree of uncertainty will be getting larger, according as the radius is getting larger because of its nonlinearity of the relations between effective radius and the brightness temperature differences as in Fig. 1, when we analyze all the pixels assuming the $100 \%$ sub-pixel cloud fraction. Future studies of further validation and correction method of sub-pixel cloud fraction are needed.

\section{Acknowledgments}

We are grateful to J. Tucker of NASA GSFC and Ryoichi Imasu of CCSR in ARGASS (AVHRR GAC dataset for Atmosphere and Surface Studies) project for providing us with AVHRR GAC data used in this study. This study was supported by NASDA OCTS/GLI projects, and the Grant-in-Aid for Scientific Research on Priority Areas (No. 08241104) of the Japanese Ministry of Education, Science, Sports and Culture. We are also thankful to Ms. Ishii of CCSR for her exertion for archiving huge data, and to A. Sinpo of the University of Tokyo for handling NCEP reanalysis data.

\section{References}

Anderson, J. and V.K. Saxena, 1996: Temporal changes of Mount Pinatubo aerosol characteristics over northern midlatitudes derived from
SAGE II extinction measurements. J. Geophys. Res., 101, 19455-19463.

Arnott, W.P., Y.Y. Dong, and J. Halett, 1994: Role of small ice crystals in radiative properties of cirrus: A case study, FIRE II, November 22, 1991. J. Geophys. Res., 99, 1371-1381.

Asano, S., A. Uchiyama, and M. Shiobara, 1993: Spectral optical thickness and size distribution of the Pinatubo volcanic aerosols as estimated by ground-based sunphotometry. J. Meteor. Soc. Japan, 71, 165-173.

Atlas, D., S.Y. Matrosov, A.J. Heymsfield, M.D. Chou, and D.B. Wolff, 1995: Radar and radiation properties of ice clouds. J. Appl. Meteor., 34, 2329-2345.

Baker, M.B., 1997: Cloud microphysics and climate. Science, 276, 1072-1078.

Baumgardner, D. and A. Korolev, 1997: Airspeed corrections for optical array probe sample volumes. J. Atmos. Ocean. Tech., 14, 1224-1229.

Beck, H.G., J.M. Davis, and S.K. Cox, 1996: Radiative properties of cirrus clouds derived from surface interferometric measurements. J. Appl. Meteor., 35, 1240-1248.

Bluth, G., S.D. Doiron, C.C. Schnetzler, A.J. Krueger, and L.S. Walter, 1992: Global tracking of the $\mathrm{SO}_{2}$ clouds from the June, 1991 Mount Pinatubo eruptions. Geophys. Res. Lett., 19, 151-154.

Cess, R.D., G.L. Potter, J.P. Blanchet, G.J. Boer, A.D. Del Genio, M. Deque, V. Dymnikov, V. Galin, W.L. Gates, S.J. Ghan, A.A. Lacis, H. Le Treut, Z.-X. Li, X.-Z. Liang, B.J. McAvaney, V.P. Meleshko, J.F.B. Mitchell, J.-J. Morcrette, D.A. Randall, L. Rikus, E. Roeckener, J.F. Royer, U. Schlese, D.A. Sheinin, A. Slongo, A.P. Sokolov, K.E. Taylor, W.M. Washington, R.T. Wetherald, I. Yagai, and M.-H. Zhang, 1990: Intercomparison and interpretation of climate feedback processes in 19 atmospheric general circulation models. J. Geophys. Res., 95, 16601-16615.

Charlock, T.P. and V. Ramanathan, 1985: The albedo field and cloud radiative forcing produced by a general circulation model with internally generated cloud optics. J. Atmos. Sci., 42, 1408-1429.

Dowling, D.R., L.F. Radke, 1990: A summary of the physical properties of cirrus clouds. J. Appl. Meteor., 29, 970-978.

Flatau P.J. and G.L. Stephens, 1990: Light scattering by rectangular solids in the discrete-dipole approximation: a new algorithm exploiting the block-toeplitz structure. J. Opt. Soc. Am. A, 7, 593-600.

Gardiner, B.A. and J. Hallett, 1985: Degradation of in-cloud forward scattering spectrometer probe 
measurements in the presence of ice particles. J. Atmos. Oceanic Technol., 2, 171-180.

Gayet, J.F., G. Febvre, and H. Larsen, 1996: The reliability of the PMS FSSP in the presence of small ice crystals. J. Atmos. Oceanic Technol., 13, 1300-1310.

Giraud, V., J.C. Buriez, Y. Foquart, F. Parol, and G. Seze, 1997: Large-scale analysis of cirrus clouds from AVHRR data: Assessment of both a microphysical index and the cloud-top temperature. J. Appl. Meteor., 36, 664-675.

Han, Q., W.B. Rossow, and A.A. Lacis, 1994: Nearglobal survey of effective droplet radii in liquid water clouds using ISCCP data. J. Climate, 7, 465-497.

, W.B. Rossow, J. Zeng, and R. Welch, 2002: Three different behaviors of liquid water path of water clouds in aerosol-cloud interactions. J. Atmos. Sci., 59, 726-735.

Hansen, J.E., M. Sato, A. Lacis, R. Ruedy, I. Tegan, and E. Matthews, 1998: Climate forcing in the industrial era. Proc. Natl. Acad. Sci., 95, 12753-12758.

Hartmann, D.L., M.E. Ockert-Bell, and M.L. Michelsen, 1992: The effect of cloud type on earth's energy balance: Global analysis. J. Climate, 5, 1281-1304.

Heymsfield, A.J. and C.M.R. Platt, 1984: A parameterization of the particle size spectrum of ice clouds in terms of the ambient temperature and the ice water content. J. Atoms. Sci., 41, 846-855.

, 1986: Ice particles observed in a cirriform cloud at $-83^{\circ} \mathrm{C}$ and implications for polar stratospheric clouds. J. Atmos. Sci., 43, 851-855. - and L. Milochevich, 1995: Relative humidity and temperature influences on cirrus formation and evolution: observations from wave clouds and FIRE II. J. Atmos. Sci., 52, 43024326.

- and G.M. McFarquhar, 1996: High albedos of cirrus in the tropical Pacific warm pool: microphysical interpretations from CEPEX and from Kwajalein, Marshall Islands. J. Atmos. Sci., 53, 2424-2451.

and L. Milochevich, 2003: Parameterization for the cross-sectional area and extinction of cirrus and stratiform ice cloud particles. J. Atmos. Sci., 60, 936-956.

Inoue, T., 1985: On the temperature and effective emissivity determination of semi-transparent cirrus clouds by bi-spectral measurements in the $10 \mu \mathrm{m}$ window region. J. Meteor. Soc. Japan, 63, 88-99.

- 1987: A cloud type classification with NOAA 7 split-window measurements. J. Geophys. Res., 92, 3991-4000.
1989: Features of clouds over the tropical pacific during northern hemispheric winter derived from split window measurements. J. Meteor. Soc. Japan, 67, 621-637.

IPCC (Intergovernmental Panel on Climate Change), 1996: Climate Change 1995: The Science of Climate Change. Houghton, J.T., L.G. Meira, B.A. Callander, N. Harris, A. Kattenberg, and K. Maskell, Eds., Cambridge Univ. Press, New York, 572pp.

- 2001: Climate Change 2001: The Scientific Basis. Y. Ding, D.J. Griggs, M. Noguer, P.J. van der Linden, X. Dai, K. Maskell, C.A. Johnson, Eds., Cambridge Univ. Press, New York, 881pp.

Jensen, E.J., O.B. Toon, D.L. Westphal, S. Kinne, and A.J. Heymsfield, 1994: Microphysical modeling of cirrus 1. Comparison with 1986 FIRE IFO measurements. J. Geophys. Res., 99, 10421-10442.

Kawamoto, K., T. Nakajima, and T.Y. Nakajima, 2001: A global determination of cloud microphysics with AVHRR remote sensing. J. Climate, 14, 2054-2068.

Kneizys, F.X., E.P. Shettle, L.W. Abreu, J.H. Chetwynd, G.P. Anderson, W.O. Gallery, J.E.A. Selby, and S.A. Clough, 1988: Users guide to LOWTRAN 7. AFGL-TR-88-0177, Air Force Geophys. Lab., Hanscom AFB, MA 01731.

—, E.P. Shettle, G.P. Anderson, L.W. Abreu, J.H. Chetwynd, J.E.A. Selby, S.A. Clough, and W.O. Gallery, 1990: LOWTRAN 7 Revision 4.0. Air Force Geophys. Lab., Bedford, Mass.

Knollenberg, R.G., 1970: The optical array: An alternative to scattering or extinction for airborne particle size determination. J. Appl. Meteor., 9, 86-103.

— K. Kelly, and J.C. Wilson, 1993: Measurements of high number densities of ice crystals in the tops of tropical cumulonimbus. J. Geophys. Res., 98, 8639-8664.

Kosarev, A.L. and I.P. Mazin, 1991: An empirical model of physical structure of upper layer clouds. Atmos. Res., 26, 213-228.

Liao, X., D. Rind, and W.B. Rossow, 1995a: Comparison between SAGE II and ISCCP highlevel clouds, Part I: Global and zonal mean cloud amounts. J. Geophys. Res., 100, 11211135.

, D. Rind, and W.B. Rossow, 1995b: Comparison between SAGE II and ISCCP high-level clouds, Part II: Locating cloud tops. J. Geophys. Res., 100, 1137-1147.

Lin, X. and J.A. Coakley, Jr., 1993: Retrieval of properties for semitransparent clouds from multispectral infrared imagery data. J. Geophys. Res., 98, 18501-18514. 
Liou, K.N., 1972: Light scattering by ice clouds in the visible and infrared: A theoretical study. $J$. Atmos. Sci., 29, 524-536.

- 1986: Influence of cirrus clouds on weather and climate processes: A global perspective. Mon. Wea. Rev., 114, 1167-1199.

Mace, G.G., E.E. Clothiaux, and T.P. Ackerman, 2001: The composite characteristics of cirrus clouds: Bulk properties revealed by one year of continuous cloud radar data. J. Climate, 14, 2185-2203.

Macke, A., 1993: Scattering of light by polyhedral ice crystals. Appl. Opt., 32, 2780-2788.

Mauldin, L.E., III, N.H. Zaun, M.P. McCormick, J.H. Guy, and W.R. Vaughn, 1985: Stratospheric Aerosol and Gas Experiment II instrument: A functional description. Opt. Eng., 24, 307-312.

McClatchey, R.A., R.W. Fenn, J.E.A. Selby, F.E. Volz, and J.S. Garing, 1972: Optical Properties of the Atmosphere (3rd ed.). U.S. Air Force Cambridge Res. Lab. AFCRL-TR-72-0497, Hanscom AFB, MA.

McCormick, M.P., 1987: SAGE II: An overview. Adv. Space Res., 7, 319-326.

McFarquhar, G.M. and A.J. Heymsfield, 1997: Parameterization of tropical cirrus ice crystal size distributions and implications for radiative transfer: results from CEPEX. J. Atmos. Sci., 54, 2187-2200.

Miloshevich, L.M. and A.J. Heymsfield, 1997: A balloon-borne continuous cloud particle replicator for measuring vertical profiles of cloud microphysical properties: Instrument design, performance, and collection efficiency analysis. J. Atmos. Oceanic Technol., 14, 753-768.

Mishchenko, M.I., W.B. Rossow, A. Macke, and A.A. Lacis, 1996: Sensitivity of cirrus cloud albedo, bi-directional reflectance and optical thickness retrieval accuracy to ice particle shape. J. Geophys. Res., 101, 16973-16985.

Nakajima, T. and M. Tanaka, 1986: Matrix formulations for the transfer of solar radiation in a plane-parallel scattering atmosphere. $J$. Quant. Spectrosc. Radiat. Transfer, 35, 13-21. - and M. Tanaka, 1988: Algorithms for radiative intensity calculations in moderately thick atmospheres using a truncation approximation. J. Quant. Spectrosc. Radiat. Transfer., 40, 51-69.

Okamoto, H., A. Macke, M. Quante, and E. Raschke, 1995: Modeling of backscattering by nonspherical ice particles for the interpretation of cloud radar signals at $94 \mathrm{GHz}$ : An error analysis. Contrib. Atmos. Phys., 68, 319-334.

- S. Iwasaki, M. Yasui, H. Horie, H. Kuroiwa, and H. Kumagai, 2003: An algorithm for retrieval of cloud microphysics using $95-\mathrm{GHz}$ cloud radar and lidar. J. Geophys. Res., 108, 4226, doi: 10.1029/2001JD001225.

Ou, S.C., K.N. Liou, W.M. Gooch, and Y. Takano, 1993: Remote sensing of cirrus cloud parameters using Advanced Very-High-Resolution Radiometer 3.7- and 10.9- $\mu$ m channels. Appl. Opt., 32, 2171-2180.

, K.N. Liou, Y. Takano, N.X. Rao, Q. Fu, A.J. Heymsfield, L.M. Miloshevich, B. Baum, and S.A. Kinne, 1995: Remote sounding of cirrus cloud optical depths and ice crystal sizes from AVHRR data: Verification using FIRE II IFO measurements. J. Atmos. Sci., 52, 4143-4158.

, K.N. Liou, and B.A. Baum, 1996: Detection of multilayer cirrus cloud system using AVHRR data: Verification based on FIRE II IFO composite measurements. J. Appl. Meteor., 35, 178-191.

Prata, A.J., 1989: Observations of volcanic ash clouds in the 10-12 micron window using AVHRR/2 data. Int. J. Remote Sensing, 10, 751-761.

Ramanathan, V., 1987: The role of Earth radiation budget studies in climate and general circulation research. J. Geophys. Res., 92, 4075-4095. , R.D. Cess, E.F. Harrison, P. Minnis, B.R. Barkstrom, E. Ahmad, and D. Hartmann, 1989: Cloud-radiative forcing and climate: Results from the Earth Radiation Budget Experiment. Science, 243, 57-63.

Randall, D.A., Harshvardhan, D.A. Dazlich, and T.G. Corsetti, 1989: Interaction among radiation, convection, and large-scale dynamics in a general circulation model. J. Atmos. Sci., 46, 1943-1970.

Rossow, W.B. and R.A. Schiffer, 1991: ISCCP cloud data products. Bull. Amer. Meteor. Soc., 72, $2-20$.

—, A.W. Walker, D.E. Beuschel, and M.D. Roiter, 1996: International Satellite Cloud Climatology Project (ISCCP) documentation of new cloud datasets. WMO/TD737, World Climate Research Programme (ICSU and WMO), $115 \mathrm{pp}$. and R.A. Schiffer, 1999: Advances in understanding clouds from ISCCP. Bull. Amer. $\mathrm{Me}$ teor. Soc., 11, 2261-2287.

Sassen, K. and G.C. Dodd, 1989: Haze particle nucleation simulations in cirrus clouds and applications for numerical and lidar studies. $J$. Atmos. Sci., 46, 3005-3014.

, 1992: Evidence for liquid-phase cirrus cloud formation from volcanic aerosols: Climatic implications. Science, 257, 516-519.

Schiffer, R.A. and W.B. Rossow, 1985: ISCCP global radiance data set: A new resource for climate research. Bull. Amer. Meteor. Soc., 66, 779784 . 
Spinhirne, J.D., W.D. Hart, and D.L. Hlavka, 1996: Cirrus infrared parameters and shortwave reflectance relations from observations. J. Atmos. Sci., 53, 1438-1458.

Stamnes, K., S.-C. Tsay, W. Wiscomb, and K. Jayaweera, 1988: Numerically stable algorithm for discrete-ordinate-method radiative transfer in multiple scattering and emitting layered media. Appl. Opt., 27, 2502-2509.

Stephens, G.L., S.C. Tsay, P.W. Stackhouse Jr., and P.J. Flatau, 1990: The Relevance of the Microphysical and Radiative Properties of Cirrus Clouds to Climate and Climatic Feedback. $J$. Atmos. Sci., 47, 1742-1753.

Stowe, L.L., H.Y. Mitchael, T.F. Eck, C.G. Wellemeyer, H.L. Kyle, and the Nimbus-7 cloud data processing team, 1989: Nimbus-7 Global cloud climatolorgy. Part II: First Year Results. J. Climate, 2, 671-709. , R.M. Carey, and P.P. Pellegrino, 1992: Monitoring the Mt. Pinatubo aerosol layer with NOAA/11 AVHRR data. Geophys. Res. Lett., 19, 159-162.

Strom, J., B. Strauss, T. Anderson, F. Schroder, J. Heintzenberg, and P. Wendling, 1997: In situ observations of the microphysical properties of young cirrus clouds. J. Atmos. Sci., 54, $2542-2553$.

Suzuki, T., M. Tanaka, and T. Nakajima, 1993: The microphysical feedback of cirrus cloud in climate change. J. Meteor. Soc. Japan, 71, 701-714.

Takano, Y. and K.N. Liou, 1993: Transfer of polarized infrared radiation in optically anisotropic media: Application to horizontally oriented crystals. J. Opt. Soc. Am. A, 52, 818-837.

Wang, P.H., P. Minnis, M.P. McCormick, G.S. Kent, and K.M. Skeens, 1996: A 6-year climatology of cloud occurrence frequency from Stratospheric Aerosol and Gas Experiment II observations (1985-1990). J. Geophys. Res., 101, 2940729429.

Wielicki, B.A., R.D. Cess, M.D. King, D.A. Randall, and E.F. Harrison, 1995: Mission to planet Earth: Role of clouds and radiation in climate. Bull. Amer. Meteor. Soc., 76, 2123-2153.

Wylie, D.P., W.P. Menzel, H.M. Woolf, and K.I. Strabala, 1994: Four years of global cirrus cloud statistics using HIRS. J. Climate, 7, 19721986.

and W.P. Menzel, H, 1999: Eight years of high cloud statistics using HIRS. J. Climate, 12, 170-184. 